\title{
Critical appraisal of the safety and efficacy of insulin detemir in glycemic control and cardiovascular risk management in diabetics
}

This article was published in the following Dove Press journal:

Diabetes, Metabolic Syndrome and Obesity:Targets and Therapy 19 June 2010

Number of times this article has been viewed

Jean-Pierre Le Floch

Department of Diabetology, Medical Clinic, Villecresnes, France
Correspondence: Jean-Pierre Le Floch Department of Diabetology, Medical Clinic, 8 Boulevard Richerand, 94440 Villecresnes, France

$\mathrm{Tel}+33$ I45955 757

Fax +33 I45697584

Email jplefloch@dietvill.com
Abstract: Insulin detemir is an analog of human insulin designed to provide a long duration of basal insulin action. This is achieved by protracted absorption from the injection depot, which results in part from increased self-association of insulin detemir molecules and in part from reversible albumin binding. Subsequent albumin binding in the circulation is thought to buffer changes in the effects at target tissues that could otherwise arise from variability in absorption rate. In consequence, insulin detemir has shown a less variable pharmacodynamic profile than alternative basal insulins; this manifests as more consistent temporal glucose reduction profiles in repeat-clamp studies. In clinical trials, insulin detemir has been characterized by consistent risk reductions in hypoglycemia, as well as reduced weight gain in comparison with other basal insulins. Given some recent associations that have been made in prospective and epidemiologic studies between glucose variability and/or hypoglycemia and increased cardiovascular risk, and the long-known association between excess weight and cardiovascular risk, it is possible that the clinical profile of insulin detemir may carry prognostic value with regard to cardiovascular safety, although this is yet to be substantiated. There have also been some concerns raised recently over the use of insulin analogs and cancer risk, but available clinical data and the receptor interaction profile of insulin detemir suggest no excess in risk in comparison with human insulin therapy. Optimal approaches for the clinical use of insulin detemir have been emerging through an increasing clinical study base, and the analog is becoming established as a potentially valuable therapy option.

Keywords: insulin detemir, type 2 diabetes, glucose variability, hypoglycemia, weight gain

\section{Introduction}

Insulin therapy is fundamental in the treatment of type 1 diabetes, and there is a large consensus that its use should be optimized, taking advantage of new technologies such as rapid- and long-acting analogs (combined in basal-bolus regimens) and new devices for insulin delivery (such as insulin pumps) and continuous glucose monitoring. The objective is to mimic the natural dynamic patterns of insulin secretion to recreate as closely as possible the physiologic glucose regulation observed in nondiabetic patients, thereby preventing diabetic complications. ${ }^{1}$

Although the prevalence of type 1 diabetes appears to be relatively constant over time, that of type 2 diabetes is rising to pandemic levels, leading to an increased need for this condition to be managed in primary care. The range of treatments for type 2 diabetes is growing, but insulins are usually required eventually. Primary care providers may find the complexity of choices available daunting, particularly the responsibility for initiating and advising on insulin injection therapy. A successful shift to primary care will require aid from specialist support. ${ }^{2}$ 
Although a sophisticated approach to insulin, including insulin analogs and delivery systems, is important in type 2 diabetes, the association of this condition with insulin resistance, overweight and other cardiovascular $(\mathrm{CV})$ risk factors in the "metabolic syndrome" requires a multifaceted treatment approach, likely to involve drugs designed to improve $\mathrm{CV}$ prognosis, such as antihypertensives, antiplatelet agents, lipid-lowering agents, and even appetite suppressants. Smoking cessation, adapted diet, and physical activity are also key components of disease management. There is also a need for regular reassessment of treatment as the patient's diabetes (and associated morbidity) progresses. ${ }^{3}$

This is all challenging enough, but making good treatment choices and advising upon this subject has been further complicated by new revelations about patient outcomes with well-established therapies. It was assumed until recently, based on landmark study data, eg, the UK Prospective Diabetes Study (UKPDS) and Diabetes Control and Complications Trial (DCCT), that patient prognosis would benefit from aggressive blood glucose reduction to levels as close to euglycemia as achievable. Thus, ambitious titration of insulin throughout the natural history of diabetes has been advocated. However, some recent studies, including the Action to Control Cardiovascular Risk in Diabetes (ACCORD),${ }^{4}$ Action in Diabetes and Vascular Disease: Preterax and Diamicron MR Controlled Evaluation $(\text { ADVANCE) })^{5}$ and Veterans Affairs Diabetes Trial (VADT) ${ }^{6}$ designed to assess whether aggressive risk factor management could improve $\mathrm{CV}$ prognosis in high-risk type 2 diabetes patients, raised concerns that overzealous blood glucose reduction might not be beneficial, ${ }^{7,8}$ with the ACCORD study suggesting a slight excess in CV mortality associated with intensive glucose reduction. This observation is not fully understood, but contrasts late follow-ups of the $\mathrm{DCCT}^{9}$ and $\mathrm{UKPDS}^{10}$ cohorts, where a CV disease (CVD) benefit emerged in patients originally assigned to more intensive glucose reduction, despite later convergence of $\mathrm{HbA}_{1 \mathrm{c}}$. It was therefore suggested that poor control early in the natural history of diabetes has a "legacy effect" (otherwise termed "metabolic memory"), whereby the contribution of hyperglycemia to atherosclerotic processes is made early in the disease process, with macrovascular damage irreversible by later blood glucose reduction, which may even be harmful. It has been suggested that hypoglycemia might be the culprit that precipitates $\mathrm{CV}$ events in patients with established atherosclerotic disease, ${ }^{11}$ although this hypothesis cannot explain with certainty the observations made in ACCORD/ ADVANCE, where other influences on CVD mortality may have applied, eg, pharmacologic actions/interactions of the therapies used, or the successful minimization of $\mathrm{CV}$ events by multiple risk factor management to rates at which glycemic control has little influence. ${ }^{7,8}$ Subset analysis of recent landmark studies suggests that patients given intensive therapy before their diabetes becomes too advanced are most able to achieve good glycemic control, with a low rate of hypoglycemia and an improved long-term health prognosis. ${ }^{4-7}$ However, a recent retrospective study highlighted the high risk of mortality observed in patients with low $\mathrm{HbA}_{1 \mathrm{c}}$ levels. ${ }^{12}$ Although interpretation remains difficult because of the study design and the lack of information on previous stages of diabetes, this study suggests that hypoglycemia could be highly deleterious and should be prevented.

Thus, a consensus is emerging that, alongside active management of other risk factors, good glycemic control must be established and maintained from diagnosis, with insulin initiated as soon as $\mathrm{HbA}_{1 \mathrm{c}}$ levels begin to rise despite optimal use of antidiabetic drug therapies. ${ }^{1,7}$ In this setting, the low incidence of hypoglycemia incurred when modern insulin analogs are used ${ }^{13}$ also appears to be a particularly attractive property, with potential to limit $\mathrm{CV}$ risk.

Yet further uncertainty has recently arisen, however, following a series of studies that explored a putative link between the use of insulin glargine and cancer risk, all based on retrospective database analyses. ${ }^{14-17}$ While more reassuring data have since been provided, ${ }^{18,19}$ these publications have increased awareness in the diabetes community of the link between diabetes, its treatments, and the risk of cancer. ${ }^{20}$ Reassuringly, in this context, metformin is emerging as a therapy with potential benefits, ${ }^{21-23}$ but we may need to be mindful of potential differences between insulins. ${ }^{24}$

In the context of these new considerations, this review summarizes what we have learned about the safety and efficacy of the basal insulin analog, insulin detemir (Levemir ${ }^{\circledR}$, Novo Nordisk, Bagsværd, Denmark). As is the case for most glucose-lowering therapies, there are few data with which to evaluate the effect of insulin detemir directly on morbid outcomes over long-term treatment, so we must consider the surrogates usually measured in studies, such as blood glucose control, weight gain, biomarkers of CV risk, and hypoglycemia. This review also considers practical issues in the hope of advising on how to achieve the most favorable clinical outcomes when using insulin detemir.

A focus on insulin detemir is important because it is one of the candidates that can be used in a basal + oral regimen where, in type 2 diabetes, basal insulin is initiated simply by adding a once-daily injection to drug therapy. With attention 
to titration, this regimen achieves important improvements in glycemic control with a low risk of hypoglycemia, ${ }^{25}$ and is therefore an increasingly popular approach to insulin initiation, especially in primary care. The strategy of initiating insulin with a basal rather than prandial or premixed regimen was recently reinforced by three-year follow-up data from the $4 \mathrm{~T}$ study, in which patients starting insulin therapy with detemir achieved glycemic control after three years equivalent to that of comparator regimens (premixed- or bolus insulin-based), but had lower burdens of hypoglycemia and weight gain. ${ }^{26,27}$

\section{Pharmacologic profile of insulin detemir}

The basal insulin analogs were developed in response to the widely recognized limitations of traditional basal insulin formulations, such as neutral protamine Hagedorn (NPH) insulin, in which protamine is used to retard the absorption of subcutaneously injected human insulin. NPH insulin is characterized by a mean duration of action that falls well short of 24 hours, so it ideally requires twice-daily dosing. Perhaps more concerning is the fact that an injected dose of NPH insulin absorbs with a pronounced peak, the degree and exact timing of which can vary considerably between injections. ${ }^{28}$ This characteristic can precipitate hypoglycemia, with nocturnal events possible after evening injection. Nocturnal hypoglycemia is especially feared by patients, and will ultimately limit dose titration.

Another limitation of conventional insulin therapy is that subcutaneous injection is followed by absorption into the systemic circulation rather than direct delivery into the portal vein, as occurs with the natural pancreatic secretion of insulin. Only intraperitoneal delivery, using implanted pumps, for instance, could achieve a more physiologic insulin tissue distribution, but this technique remains experimental. This means that peripheral tissues are unavoidably overexposed to insulin relative to the liver, and this effect may contribute to the hypoglycemia and weight gain that often typifies insulin therapy, ${ }^{29}$ as elaborated upon below.
The ideal basal insulin designed for subcutaneous injection would have a flatter and longer time-action profile than that of NPH insulin. It might also be distributed so as to exert a more physiologic pattern of action across target tissues. In view of recent concerns about insulin and cancer risk, any analog of insulin developed to achieve the above goals would also need to have a profile of receptor interactions that did not differ from human insulin.

\section{Protraction principle and pharmacokinetic profile}

In the pursuit of improved basal insulins, two different approaches have led to clinical success. The first, exemplified by insulin glargine, has been to modify the molecule to shift the isoelectric point. ${ }^{30}$ Insulin glargine features a single amino acid substitution at the terminal residue (A21) of the A chain, with two arginine residues also added to the $\mathrm{B}$ chain terminus (B31, 32). These modifications make the molecule soluble in acidic environments (as in the pharmaceutical formulation), but it forms slowly absorbed precipitates in the neutral subcutaneous depot.

Insulin detemir has a very different protraction principle. There is deletion of the terminal B chain amino acid (B30), and a fatty acid side chain (myristic acid) is attached at B29 (Figure 1). This region of the molecule was chosen because it is involved in self-association, but not in insulin receptor interaction. ${ }^{31}$ The change has the effect of enabling dihexameric complexes to form in the injection depot, as well as enabling reversible albumin binding. ${ }^{32}$ Insulin detemir is thereby retained in the injection depot and, once absorbed, further albumin binding serves to retard it in the circulation and buffer the effect of any sudden changes in absorption rate. ${ }^{33}$ This property might explain the observation in repeat-clamp studies that insulin detemir is characterized by significantly lower within-subject variability in blood glucose-lowering action from injection to injection compared with NPH insulin ${ }^{28}$ and insulin glargine. ${ }^{28,34}$

In many of the clinical studies performed before registration, insulin detemir was administrated twice daily (or else this option was available), so its duration of action was

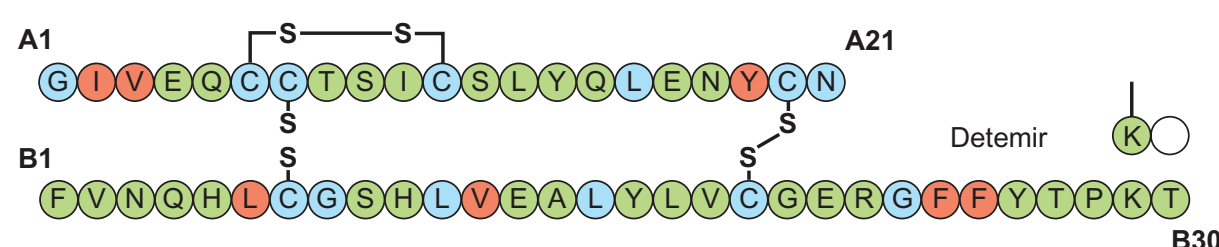

Figure I Molecular structure of insulin detemir. 
commonly considered to be lower than that of insulin glargine, and insufficient to meet 24-hour basal insulin requirements from a once-daily injection regimen. For instance, whereas the duration of action of glargine was considered to be 20-24 hours, the duration of action of detemir was reported to be 6-23 hours in a major treatment guideline publication. ${ }^{1}$ However, the mean duration of action of insulin detemir in a clamp study in patients with insulin-treated type 2 diabetes (fasting C-peptide $\leq 1 \mathrm{nmol} / \mathrm{L}$ ) was identical to that of insulin glargine at clinically relevant doses (Figure 2). ${ }^{34}$ The relative blood glucose-lowering profiles of the two available basal insulin analogs have been reviewed in detail by Heise and Pieber, ${ }^{35}$ who have highlighted the importance of the withinsubject reproducibility of this profile from injection to injection. This aspect is discussed further below, but in terms of the mean time-action profile. Depending on the definitions used for beginning and end of action, the duration of effect of both detemir and glargine in clamp studies is about 24 hours. ${ }^{35}$ Therefore, insulin detemir appears to be suitable for once-daily dosing in type 2 diabetes and once- or twice-daily dosing in type 1 diabetes, where glycemic control is critically dependent at all times on exogenous insulin supply.

While the basal insulin analogs are commonly described as having a long, flat, and peakless action, this should be considered with caution with reference to short-acting insulin. As evident in Figure 2, their mean pharmacodynamic profile (following a single subcutaneous injection) is not totally flat, showing a slow increase in blood glucoselowering action that reaches a maximum after about eight hours, before a gradual decline to baseline values at about 24 hours. There is currently a paucity of data concerning how (or if) the glucose-lowering profile across 24 hours changes with repeated once- or twice-daily dosing.

\section{A more physiologic tissue distribution?}

A potentially unique feature of the pharmacology of insulin detemir is that its tissue distribution may be different from that of other exogenous insulins. This is evidenced by the consistent finding in clinical trials that insulin detemir causes less weight gain than other basal insulins, ${ }^{29,36}$ as discussed further below. The mechanism responsible for this observation remains unproven, but there are two main theories, both involving albumin binding. One idea is that, compared with traditional insulins, circulating detemir has relatively reduced access to peripheral tissues such as adipose tissue as a result of albumin binding, whereas albuminbound detemir does have access to hepatocytes via the open endothelial fenestrae in hepatic sinusoids. ${ }^{29,37}$ As a result, more of the glucose-lowering effect of detemir (compared with other exogenous insulins) is accounted for by reduced hepatic glucose output as opposed to increased peripheral glucose uptake. ${ }^{37}$ This might imply that insulin detemir has a relatively reduced propensity for stimulating lipid storage in adipocytes, and implies a more physiologic gradient of action between the liver and periphery. A relatively greater effect of detemir on hepatic glucose output versus peripheral glucose uptake in comparison with NPH insulin was also demonstrated during enforced hypoglycemia; reassuringly, counterregulatory responses and symptom awareness were fully preserved. ${ }^{38}$ The other theory advanced to account for the relative weight gain-sparing profile of detemir is that its albumin-binding properties result in an equilibrium across the blood-brain barrier whereby an increased proportion of unbound detemir in cerebrospinal fluid leads to appetite-suppressing effects in the central nervous system and/or improved homeostasis of lipid metabolism..$^{39-41}$
A

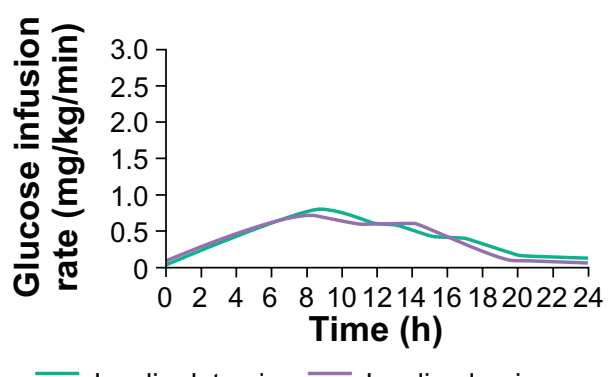

B

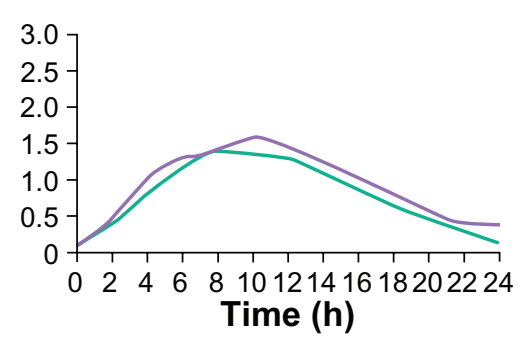

C

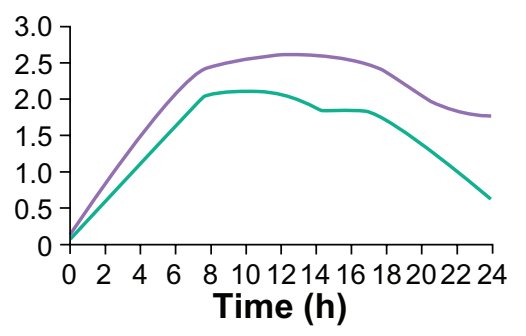

Figure 2 Mean 24-hour action profiles of three doses of insulin detemir and insulin glargine (A: $0.4 \mathrm{U} / \mathrm{kg} ; \mathrm{B}: 0.8 \mathrm{U} / \mathrm{kg}$; C: I.4 U/kg) in a glycemic clamp study in patients with insulin-requiring type 2 diabetes (fasting C-peptide concentration $\leq$ I nmol/L). Reprinted from Klein O, Lynge J, Endahl L, Damholt B, Nosek L, Heise T. Albuminbound basal insulin analogues (insulin detemir and NN344): Comparable time-action profiles but less variability than insulin glargine in type 2 diabetes. Diabetes Obes Metab. 2007;9:290-299..$^{34}$ Copyright (C 2007, with permission from John Wiley and Sons. ${ }^{34}$ 


\section{Binding properties and molecular safety}

As noted above, concerns have recently been raised about a possible association between insulin glargine and risk of cancer. ${ }^{14-17,20}$ This remains a debated issue following criticism of the methodology of some of these studies, ${ }^{42}$ and the failure of subsequent analyses of the insulin glargine database to identify any increased risk versus comparators. ${ }^{18,43}$ Nevertheless, the original investigation ${ }^{14}$ was undertaken based on the a priori hypothesis that insulin glargine might have increased mitogenic properties because it has been associated in some laboratory experiments and cell lines with increased affinity for the insulin-like growth factor I (IGF-I) receptor and/or increased mitogenicity compared with human insulin or other analogs. ${ }^{44-46}$ It is biologically plausible that insulin therapy could accelerate the development of existing subclinical tumors within timeframes of less than two years if these lesions express appropriate receptors. ${ }^{24}$ Insulin is a growth factor, and, as noted above, peripheral tissues may be exposed to supraphysiologic insulin levels when insulin is injected subcutaneously, especially at the high doses often used in type 2 diabetes. It is also possible that, while target tissues may be resistant to insulin in diabetes, neoplasms expressing insulin or IGF-I receptors may not be. Any risk could therefore potentially be increased if an insulin analog had receptorbinding properties that were inadvertently and inappropriately modified. In fact, the only insulin analog shown to have tumor-promoting properties (at high doses) in an animal model was the early analog X10, and this was found to have increased residency at the insulin receptor as well as increased IGF-I receptor affinity. ${ }^{44,47}$ Insulin analogs possessing either of these two properties were shown to have increased mitogenic properties in cell line studies. ${ }^{44}$

In the case of insulin detemir, the receptor-binding profile appears to be benign because insulin receptor residence time is actually reduced relative to human insulin, while the affinity ratio for the insulin receptor:IGF-I receptor is fully preserved relative to human insulin. ${ }^{44} \mathrm{~A}$ retrospective analysis of the manufacturer's clinical trials database showed a lower incidence of cancer associated with insulin detemir than NPH insulin ( 0.36 versus 0.92 events per 100 patient-years' exposure, $P<0.05$ ), while there was a nonsignificantly lower incidence versus insulin glargine ( 0.87 versus 1.27 , not statistically significant), albeit based on a very small dataset by epidemiologic study standards. ${ }^{19}$ The discrepancy in absolute event rate between these two comparisons probably reflects the fact that a higher percentage of the trials versus glargine were undertaken in type 2 diabetes.

\section{Clinical efficacy and safety profile of insulin detemir Glycemic control, variability, and risk of hypoglycemia}

Insulin detemir has been subject to many clinical trials in type $1^{48-59}$ and type 2 diabetes. ${ }^{60-67}$ The data are therefore far too numerous to discuss in detail in this review, but key endpoints and trial details are tabulated in Tables 1, 2, and 3 and discussed here in more general terms. When assessing these clinical trial data, it is important to be aware of a couple of caveats. Firstly, trials of insulin detemir versus NPH insulin cannot be readily blinded because NPH is presented as a cloudy suspension that requires shaking before injection, whereas insulin detemir is presented as a clear solution. Therefore, the studies have employed open designs; however, the potential for bias is likely to be reduced by the fact that most of the endpoints assessed are objectively measured.

\section{Glycemic control and trial design}

Another important consideration is that, in order to ensure equivalence in insulin trials, it is customary to apply equal glycemic targets and/or titration algorithms. Moreover, trials are often designed to test noninferiority with regard to $\mathrm{HbA}_{1 \mathrm{c}}$ as the primary endpoint. Consequently, unless tolerability becomes a significant barrier, equal levels of glycemic control are generally seen, meaning that differences between insulins are more often manifest in the secondary tolerability endpoints. This has been the general case in the insulin detemir trials program, but statistically significant advantages in glycemic control were obtained with insulin detemir versus $\mathrm{NPH}$ insulin in the longest trial (in type 1 diabetes) after two years, with this trial allowing continual dose titration. ${ }^{54}$ This might imply that the confidence to drive titration is gained over time with increasing familiarity, and thus further longerterm research would be of interest.

Superior efficacy (as well as superior tolerability) was also obtained when insulin detemir combined in a basal + bolus regimen with insulin aspart was compared with an all human insulin basal + bolus regimen. ${ }^{53}$ This might seem an unfair comparison, but, as argued previously, ${ }^{68}$ basal analogs were originally designed for use in combination with rapidacting analogs, and because the short action of the latter often necessitates a compensatory increase in basal insulin dose, it may be that any advantages of the bolus analogs will be undermined by the imperfections of a basal insulin. Thus, an all-analog basal + bolus regimen allows both components to 


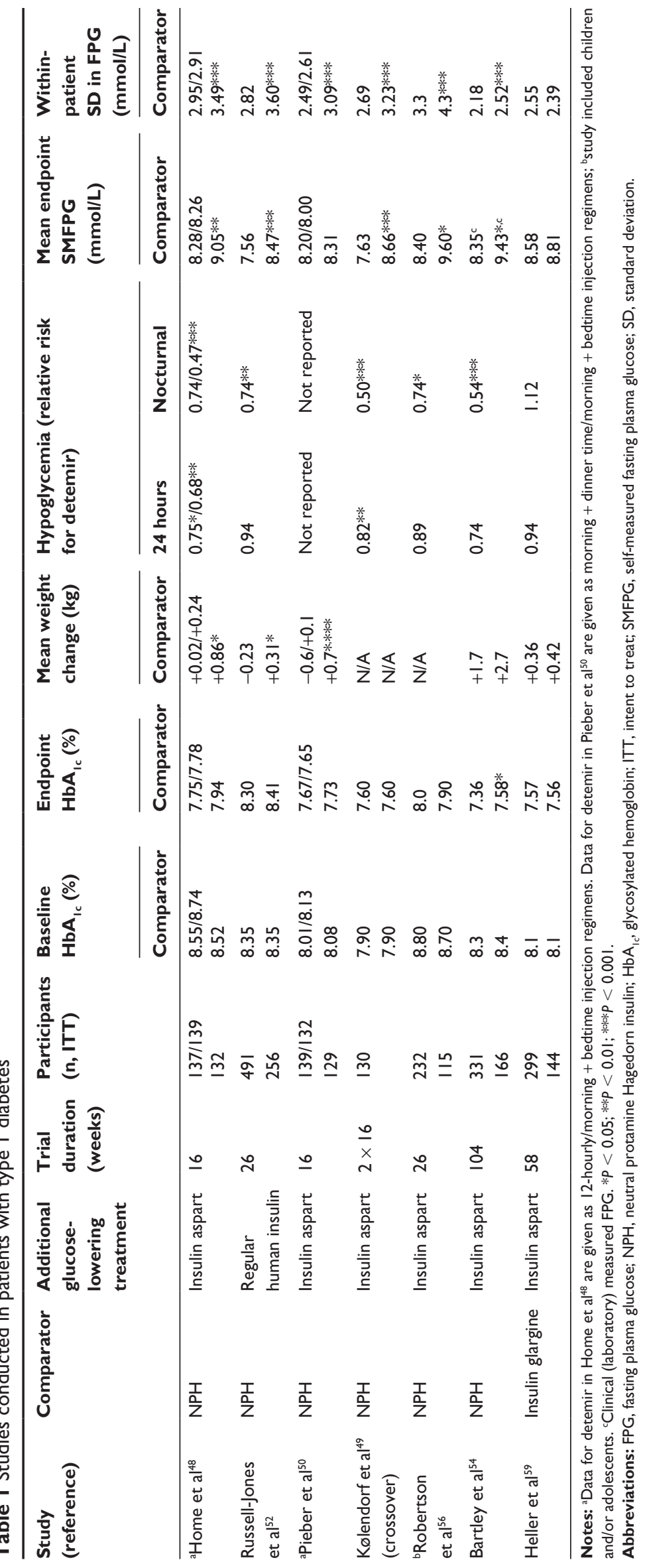




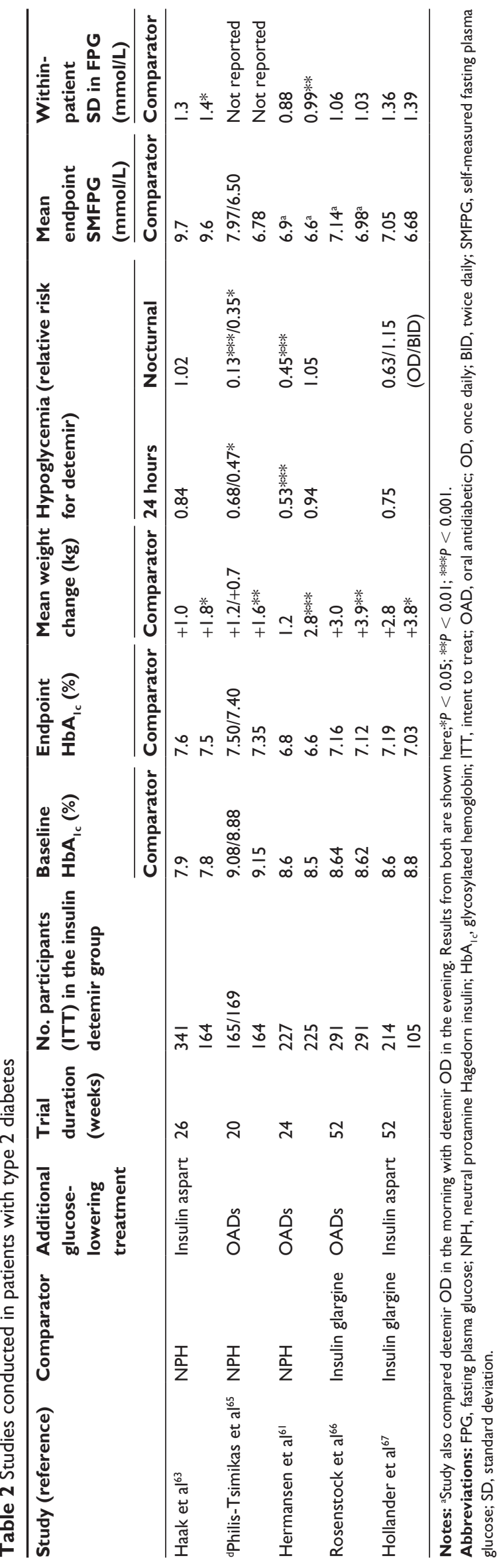

be used to full advantage. Clearly, the results of the Hermansen study $^{53}$ (Table 3) show that a superior efficacy:tolerability ratio can be achieved with an analog regimen, at least in type 1 diabetes. The issues of how dosing frequency and titration protocols affect glycemic control are discussed below.

\section{Glycemic variability: Prognostic importance often overlooked}

One endpoint that has been included in the insulin detemir trials that had not been commonly assessed previously is intrasubject blood glucose variability. This follows the finding in repeat-clamp studies of reduced variability of effect associated with insulin detemir versus NPH and glargine. ${ }^{28,69}$ Glucose variability associated with insulin therapy is not easy to measure in ambulatory patients, so the rather crude surrogate of standard deviation in fasting glycemia has often been used. Nevertheless, as predicted from the clamp data, detemir was consistently associated with a reduction in this parameter compared with NPH insulin, and this was particularly marked in type 1 diabetes (see Tables 1, 2, and 3). The apparent reduction in this advantage (and in absolute values for this parameter) in type 2 diabetes might relate to the effect of endogenous insulin-buffering differences between the exogenous insulin comparators. One study additionally assessed glucose variability in a subgroup using a continuous glucose monitoring system, ${ }^{52}$ and this again showed reduced variability with insulin detemir compared with NPH insulin (Figure 3).

Glycemic variability is often given little attention in daily clinical practice, but may be of prognostic importance. There is evidence that glucose variability, particularly when assessed by high postprandial glycemic excursions, adversely influences $\mathrm{CV}$ prognosis, ${ }^{70}$ highlighting the potential importance of insulin regimens and self-management programs that limit glycemic excursions and maintain glucose stability as effectively as possible. Of course, basal insulins per se are not intended to curtail postprandial blood glucose rises effectively, but a regimen that combines the reproducible basal insulin action of detemir with an intervention designed to achieve postprandial glucose control (eg, a rapid acting insulin analog) might be expected to benefit glycemic stability. Current thinking is that glucose variability can lead to increased oxidative stress in type 2 diabetes, ${ }^{71}$ and adversely affect $\mathrm{CV}$ prognosis. An elegant study that illustrated this mechanism was provided by Ceriello et al. ${ }^{72}$ Here, blood glucose was clamped at two levels ( 10 and $15 \mathrm{mmol} / \mathrm{L}$ ) and shown to result in concentration-dependent endothelial dysfunction 


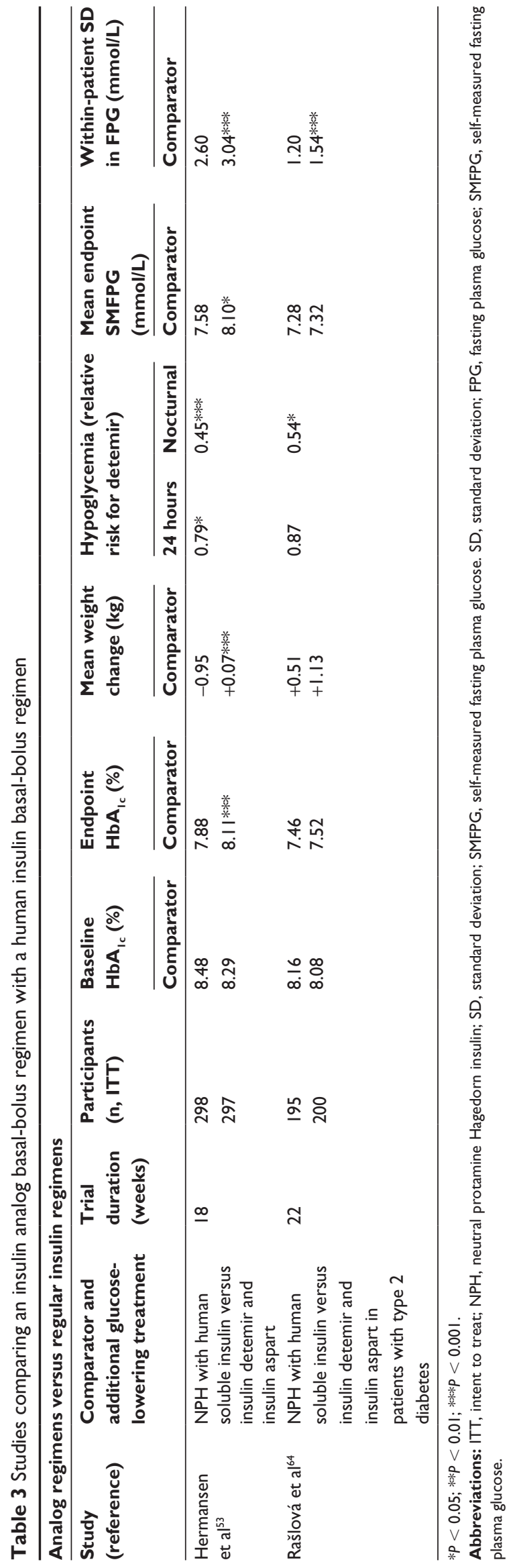

(flow-mediated dilatation) and biomarkers of oxidative stress in both normal and type 2 diabetic subjects. When glucose was oscillated between 5 and $15 \mathrm{mmol} / \mathrm{L}$ every six hours for 24 hours there were further significant increases in these parameters, above those seen even at a constant glucose level of $15 \mathrm{mmol} / \mathrm{L}$. The effects of oscillating glucose, however, on both endothelial function and biomarkers of oxidative stress could be offset by administration of the antioxidant vitamin $\mathrm{C}$. These data suggest that oscillating glucose might have more deleterious effects on $\mathrm{CV}$ function and prognosis than constant high glucose. This study (and hypothesis) is consistent with one by Monnier et $\mathrm{al}^{71}$ in which oxidative stress, assessed by urinary biomarkers, was shown in ambulatory patients with type 2 diabetes to be elevated versus healthy controls and to correlate with glucose variability.

An intriguing observation from the original landmark DCCT study was that the prognosis for microvascular morbidity tended to be poorer with conventional versus intensive intervention at any given level of $\mathrm{HbA}_{1 \mathrm{c}}$, leading to the suggestion that glucose variability could influence this morbidity too. ${ }^{73}$ Although this apparent observation may have been an artifact of statistical modelling, ${ }^{74}$ a recent analysis of DCCT data suggests that $\mathrm{HbA}_{1 \mathrm{c}}$ variation adds to mean $\mathrm{HbA}_{1 \mathrm{c}}$ in predicting incidence and progression of microvascular complications. $^{75}$

So far, the studies discussed would support the argument that insulins causing less glycemic variability could carry an important long-term prognostic advantage. Interestingly, however, a recent analysis of biomarkers of oxidative stress in type 1 and type 2 diabetes patients has suggested that insulin therapy may limit (and even normalize) activation of oxidative stress (versus alternative drug therapies in type 2 diabetes), regardless of the diurnal glycemic profile. ${ }^{70}$ More research is clearly required to elucidate fully the primary effects of glucose variability, and whether this remains of prognostic importance in insulin-treated patients. Nevertheless, it is worth highlighting that the differences in glucose variability observed between comparators in clamp and clinical studies of insulin detemir imply that unstable glucose control is not entirely due to patient behaviors, and must at least partly reflect insulin kinetics. ${ }^{52}$

\section{Hypoglycemia}

One of the better known possible benefits of lower glucose variability is a reduced risk of hypoglycemia, and this has been another consistent finding with insulin detemir compared with NPH insulin (Tables 1, 2, and 3). This is particularly true for nocturnal hypoglycemia, which is perhaps 


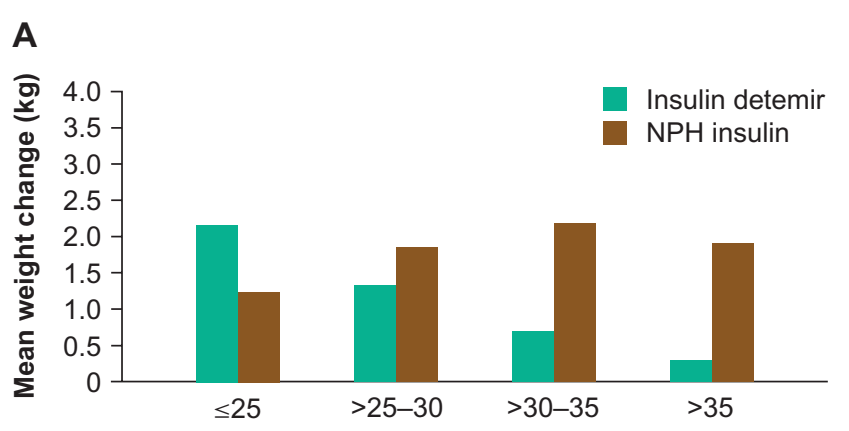

B

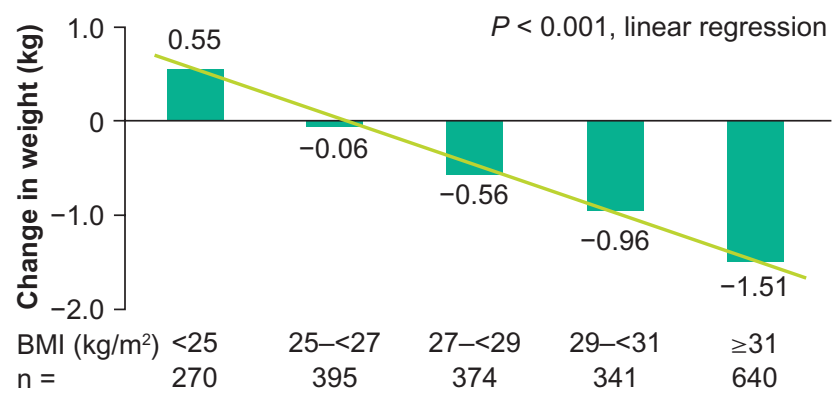

Figure 3 Weight change stratified by baseline body mass index in previously insulinnaive patients adding basal insulin to oral antidiabetic therapy. A) In a comparative treat-to-target trial. B) In the observational PREDICTIVE study. Figure 3a reprinted from Philis-Tsimikas A. Tolerability, safety and adherence to treatment with insulin detemir injection in the treatment of type 2 diabetes. Patient Prefer Adherence. 2008;2:323-332..$^{79}$ Copyright 2008, with permission from Dove Medical Press Ltd. Figure 3b reprinted from Dornhorst A, Lüddeke HJ, Sreenan S, et al; PREDICTIVE Study Group. Insulin detemir improves glycaemic control without weight gain in insulin-naïve patients with type 2 diabetes: Subgroup analysis from the PREDICTIVE study. Int J Clin Pract. 2008;62:659-665. ${ }^{81}$ Copyright (C) 2008, with permission from John Wiley \& Sons, Inc.

not surprising given that basal insulins exert more control over nocturnal glycemia than daytime glycemia, which is also influenced by food consumption, exercise pattern, and the use of mealtime bolus insulins. The risk reduction for nocturnal hypoglycemia versus NPH in type 1 diabetes has been around $30 \%$, with even greater relative risk reductions reported in type 2 diabetes. ${ }^{61,65}$ It is reassuring to note that this advantage extends to vulnerable patient groups, including children and adolescents,${ }^{58}$ and elderly populations. ${ }^{60}$

A recent analysis of data from the large observational PREDICTIVETM study provided strong evidence that the reduced risk of nocturnal hypoglycemia seen with detemir is indeed causally related to reduced glycemic variability. ${ }^{76}$ However, the reduced risk of nocturnal hypoglycemia reported for insulin detemir versus NPH (albeit from low absolute event numbers) in type 2 diabetes, in which glucose variability seems to be less of an issue, might involve a different mechanism. One possibility is that the absorption profile of NPH insulin peaks earlier than that of insulin detemir, with the maximum glucose-lowering action occurring in the early hours of the morning following evening dosing.

\section{Weight gain}

One of the most consistent findings across the insulin detemir clinical trials program was of reduced weight gain versus both NPH insulin and insulin glargine (Tables 1, 2, and 3). The mechanism responsible remains unclear, although two theories currently regarded as the most plausible are outlined above. In clinical trials in type 1 diabetes, insulin detemir has tended to be associated with unchanged weight, whereas other basal insulins have led to minor weight gain over the study periods. In type 2 diabetes trials, especially those where insulin is being initiated, insulin detemir has often been associated with a relative reduction of about $50 \%$ compared with alternative basal insulins (Table 3), and this advantage seems to be maximized when it is dosed once rather than twice daily. ${ }^{66,77}$ The absolute differences in weight gain between insulin detemir and comparators have been in the order of a just few kilograms over the study periods, but the relative advantage of detemir over NPH insulin has been found to increase with increasing baseline body mass index (BMI). ${ }^{61,78,79}$ Furthermore, the large-scale, open, observational PREDICTIVE study of the empiric use of detemir showed that patients switched from other basal insulins to detemir (within a basal-only therapy regimen) actually tended to lose weight ( $0.5-0.7 \mathrm{~kg}$ reduction, on average) despite improved glycemic control $\left(\mathrm{HbA}_{\mathrm{lc}}\right.$ reduction $\left.0.2-0.6 \%\right){ }^{80}$ Even more interesting was the finding that insulin-naïve patients initiated onto detemir in a basal insulin + oral antidiabetic drug (OAD) regimen in PREDICTIVE lost a mean $0.7 \mathrm{~kg}$ in weight despite a mean $\mathrm{HbA}_{1 \mathrm{c}}$ reduction of $1.3 \%{ }^{81}$ Again, this apparent weight benefit increased with baseline BMI (Figure 3).

Type 2 diabetes is commonly causally associated with excess weight and sedentary lifestyle, and the resulting insulin resistance, so avoidance of further weight gain might actually facilitate disease management by delaying disease progression. Overweight is also an independent risk factor for $\mathrm{CV}$ disease, and it is associated with mortality risk in type 2 diabetes. ${ }^{82}$ Whether the avoidance of a small amount of weight gain with insulin detemir will translate into a meaningful risk reduction for $\mathrm{CV}$ events will be difficult to establish, but some analyses of epidemiologic data have suggested that even small gains in weight might lead to measurable increases in CV risk. ${ }^{82,83}$ Any prognostic significance of the relative reduction in weight gain seen with insulin detemir is likely to reflect the nature of any relative change in body composition. This issue is currently under study, but data from a study in rodents suggest that much of the difference in weight gain seen between detemir and human insulin is accounted for by fat mass.$^{84}$ Furthermore, 
a study involving dual energy X-ray absorptiometry scanning of 14 insulin-treated patients randomized 1:1 to insulin detemir or NPH showed modest weight loss with detemir and weight gain with NPH (each of about $1 \mathrm{~kg}$ ), with most of the difference in weight change accounted for by visceral fat. ${ }^{85}$ This is also supported by the observation of reduced waist circumference in patients switching to detemir from NPH insulin. ${ }^{86}$

It is also worth noting that patients may be tempted to compromise their glycemic control by deliberate underdosing of insulin as a tactic to avoid weight gain, ${ }^{87-89}$ and this behavior is certainly likely to impact adversely both macro- and microvascular prognosis. Therefore, a relative reduction in weight gain could represent an important safety advantage for insulin detemir. A final point when considering the overall $\mathrm{CV}$ risk management of patients with type 2 diabetes is that the encouragement of weight loss is usually a core element of the treatment plan. ${ }^{77}$ Intervention often begins with diet and exercise, and progresses through the addition of treatments chosen for their weight-sparing properties (eg, metformin, GLP-1 mimetics). This approach is informed by the need to reduce the patient's CV risk, as well as to slow their diabetic disease progression. Insulin detemir therefore offers an option to continue rather than abandon this treatment philosophy at the point of insulin initiation. ${ }^{77}$

\section{Hyperinsulinism}

Whereas insulin is commonly dosed to achieve close to normal plasma levels in patients with type 1 diabetes, the higher doses usually necessary for patients with type 2 diabetes result in supraphysiologic plasma concentrations, which are necessary to compensate for insulin resistance. Indeed, hyperinsulinemia naturally occurs early in the type 2 diabetes disease process as a compensatory response to tissue insulin resistance and, as such, is a common component in the metabolic syndrome, associated, albeit possibly indirectly, with an increased risk of $\mathrm{CV}$ events..$^{90,91}$ Therefore, it could be involved in the unexpected results observed in some of the outcome studies discussed above, ${ }^{4,5,12}$ which imply a failure to reduce $\mathrm{CV}$ complications despite improved glycemic control. There are, however, confounding factors in these analyses, including the use of insulin secretagogue therapies (eg, sulfonylureas) and duration of diabetes. Hyperinsulinemia may also be involved in the occurrence of hypoglycemia and weight gain, while hyperstimulation of IGF-I receptors and other receptors might also increase the mitogenic risk.

Therefore, as far as possible, hyperinsulinemia should be prevented, despite the objective of lowering glycemic levels as close to normal as possible. This potential conflict high- lights the importance of diet and exercise therapy as well as the use of drugs such as metformin, and possibly glitazones, which could theoretically limit insulin requirement.

\section{Optimizing clinical success with insulin detemir}

Overall, the clinical trials program suggests that insulin detemir can be used to achieve glycemic control that is at least equivalent to conventional basal insulins, but with a reduced burden of glucose variability, hypoglycemia, and weight gain. This profile is attractive, and has been supported by various analyses of PREDICTIVE, ${ }^{61,80,92-102}$ in which some 40,000 detemir-treated patients have been followed.

Most of the original clinical trials of insulin detemir carried out in both type 1 and type 2 diabetes for registration purposes used twice-daily dosing regimens (comparing outcomes with twice-daily NPH insulin). This led many prescribers to regard insulin detemir as a basal insulin that should be given twice daily. In fact, critical reviews of outcomes from basal insulin studies have concluded that twicedaily dosing of a basal insulin, at least in type 2 diabetes, usually represents an inefficiency. ${ }^{25,77}$ It is important to realize that the duration of action of subcutaneously injected insulin is dose-proportionate, ${ }^{34,103}$ and that relatively high doses of basal insulin are administered in type 2 diabetes due to the tendency for patients to be heavy and insulin-resistant. As has been pointed out by Meneghini et al, ${ }^{77}$ even NPH insulin performs well in a once-daily regimen in this setting. ${ }^{104}$ With twice-daily administration, dose titration against two blood glucose target reading times becomes necessary (typically fasting and predinner), and this tends to escalate basal insulin dose without proportional improvement in glucose control. ${ }^{25}$ This is because the total blood glucose-lowering effect of insulin is not simply proportional to the dose given, but is highly dependent on its rate of appearance in the circulation in relation to calorie intake. ${ }^{77}$ Thus, while the slow overnight absorption of exogenously administered basal insulin is a key determinant of fasting glycemia (and hence the baseline for glucose control during the daytime), the absorption of a basal insulin formulation will have relatively little impact on postprandial glucose rises, where a coordinated rapid rise in plasma insulin is needed to curtail the glucose excursion. ${ }^{106}$ Furthermore, the advantage of less weight gain seen with insulin detemir over insulin glargine (given once daily) seems to be diminished in patients receiving detemir twice daily (and hence at higher doses) ${ }^{66}$ These observations support the view that the greatest efficiency (in terms of clinical 
benefit:dose ratio) is achieved when detemir is dosed once daily in type 2 diabetes.

In type 1 diabetes, however, lower doses of insulin tend to be used (due to lower weight of patients and their greater insulin sensitivity) and glycemic control is more critically dependent on the minute-by-minute absorption of exogenous insulin. Given that the mean duration of action of therapeutic doses of the basal insulin analogs has been reported as close to (or, in some studies, slightly below 24 hours), ${ }^{35}$ at least some patients may benefit from their basal insulin being injected more frequently than once daily, as has been reported for insulin glargine. ${ }^{106,107}$ Therefore, the present author carried out a randomized comparative study (followed by an optional guideline-directed, nonrandomized, crossover phase) of once- versus twice-daily insulin detemir used as part of basal + bolus therapy in adult patients with type 1 diabetes. ${ }^{55}$ The study showed moderate improvement of $\mathrm{HbA}_{1 \mathrm{c}}$ after four months in patients randomized to both once-daily (before dinner) and twice-daily (before breakfast and dinner) detemir, with no significant difference between these groups in glycemic control, despite a higher total insulin dose consumption associated with twice-daily detemir. Patients switching from once- to twice-daily detemir after four months showed no statistically significant improvement in $\mathrm{HbA}_{1 \mathrm{c}}$ overall, but the few patients who switched from twice- to once-daily detemir showed a decline, which was apparently explained by the simple removal of the morning basal insulin injection without compensatory changes in other insulin doses. The study concluded that once-daily injection before dinner is the most efficient way to initiate detemir in adult type 1 diabetes, although some individuals will benefit from twicedaily dosing.

Interestingly, this hypothesis was tested retrospectively using 12-month data from the French cohort of the PREDICTIVE study. ${ }^{108}$ Again, twice-daily dosing was found to be associated with no advantage in glycemic control despite higher dose consumption in the setting of basal + bolustreated type 1 and type 2 diabetes, and in basal + OAD-treated type 2 diabetes. However, it must be noted that this was not a randomized study, hence empiric choices regarding dose frequency were made.

The overall evidence outlined above suggests that optimal efficiency is obtained with once-daily insulin detemir for the majority of adult patients. Nevertheless, as can be seen in the data provided (Tables 1, 2, and 3), final $\mathrm{HbA}_{1 \mathrm{c}}$ values have fallen short of guideline targets in most clinical studies, as is the case in most insulin trials generally. In type 1 diabetes, tight glycemic control is difficult to achieve, and most of the comparative studies have followed the classic protocol of switching previously insulin-treated patients to their allocated study regimen, commenced with a short titration phase followed by a longer dose maintenance phase in which no further dose adjustment is made. In addition, most of the patients included in these controlled studies showed previously poor glycemic control, which was a criterion for inclusion. It is therefore not surprising that glycemic control did not change substantially from baseline in many of these studies (Table 1) as there was no option to carry on adjusting dose beyond the titration phase, in which patients are often becoming accustomed to a new regimen. In this respect, it is noteworthy that the Hermansen et $a l^{53}$ study of analog versus human insulin basal + bolus regimens (Table 3) showed substantial improvement only in the analog arm, highlighting the importance of matching both basal and prandial insulin kinetics to physiologic need. Only recently has a continuous titration-to-target approach been applied in studies of insulin detemir in type 1 diabetes, ${ }^{54,59}$ and here the potential of insulin analogs to improve $\mathrm{HbA}_{1 \mathrm{c}}$ becomes apparent (Table 1).

The concept of continuous titration-to-target first emerged in type 2 diabetes following the publication by Riddle et al of a study designed to test whether addition of once-daily insulin glargine to OAD therapy as a simple approach to insulin initiation could achieve substantial improvements in glycemia. ${ }^{104}$ The concept was validated and has been widely adopted subsequently, with several clinical studies of insulin detemir applying the concept successfully. ${ }^{61,65-67,97,109-111}$ A critical analysis of the type 2 diabetes titrate-to-target studies of insulin initiation with basal insulin has suggested that $\mathrm{HbA}_{1 \mathrm{c}}$ improvement is typically in the order of $1.5 \%$ using this approach, ${ }^{25}$ but since this is independent of baseline control, it follows that satisfactory levels of control are typically only reached if basal insulin is initiated before $\mathrm{HbA}_{1 \mathrm{c}}$ has risen to about $8.5 \%$. Further studies have shown that patients can successfully manage goal-directed titration of insulin detemir themselves using simple algorithms such as the ' 303 ' approach,,$^{77,97,109}$ in which the dose is adjusted by $-3,0$ or +3 units every three days, depending on the mean value of the previous three fasting plasma glucose (FPG) readings and/or occurrence of hypoglycemia. Such an algorithm may be particularly useful in primary care, and in terms of empowering patients to manage their diabetes more effectively.

There has been some recent discussion about the appropriate FPG target against which to titrate the insulin detemir dose. ${ }^{77,109}$ Pharmacokinetic/pharmacodynamic comparisons with NPH insulin suggest, consistent with the lower risk of 
nocturnal hypoglycemia reported in clinical trials, that insulin detemir typically has a later and smaller $\mathrm{C}_{\max }$ than $\mathrm{NPH}$ insulin. Following evening administration, this might coincide with the time at which prebreakfast glucose readings for titration are taken. It is therefore possible that insulin detemir could be titrated using more ambitious FPG targets than would be tolerable for NPH insulin. ${ }^{77}$ This hypothesis implies that the full advantages of insulin detemir may not have been realized in the clinical trial program.

Indeed, the feasibility of using an extremely ambitious FPG target to tolerably achieve $\mathrm{HbA}_{1 \mathrm{c}}<7.0 \%$ with insulin detemir for patients with suboptimally controlled type 2 diabetes was recently demonstrated in the TITRATETM study. ${ }^{109}$ In this 20 -week study, once-daily detemir therapy was added to the current OAD regimens in 244 insulin-naïve patients with type 2 diabetes, although dose reduction or discontinuation of sulfonylureas was permitted if patients were experiencing hypoglycemia. Patients were randomized into two groups, and each set a different FPG target, ie, either the classical $4.4-6.0 \mathrm{mmol} / \mathrm{L}$ or a lower target of $3.5-5.0 \mathrm{mmol} / \mathrm{L}$. The patients were taught how to self-titrate using the 3-0-3 algorithm described above. Thus, subjects in the 4.4-6.0 $\mathrm{mmol} / \mathrm{L}$ target group adjusted the insulin dose by +3 units if their three-day mean FPG value was $>6.1 \mathrm{mmol} / \mathrm{L}$, and by -3 units if it was $<4.4 \mathrm{mmol} / \mathrm{L}$ (no adjustment if the mean value was within the target range). Similar 3-unit dose adjustments were made based on the lower FPG target at $<3.9$ and $>5.0 \mathrm{mmol} / \mathrm{L}$. At the end of the study, $64.3 \%$ and $54.5 \%$ of subjects in the $3.9-5.0$ and 4.4-6.1 $\mathrm{mmol} / \mathrm{L}$ groups, respectively, had achieved $\mathrm{HbA}_{1 \mathrm{c}}$ levels $<7.0 \%(P=0.04$, between groups $)$. The $3.9-5.0 \mathrm{mmol} / \mathrm{L}$ group used slightly greater doses than the $4.4-6.1 \mathrm{mmol} / \mathrm{L}$ group ( $0.57 \mathrm{U} / \mathrm{kg}$ versus $0.51 \mathrm{U} / \mathrm{kg}$ at end of the study), and overall rates of hypoglycemia were low (7.73 and 5.27 events/subject/year), with only one major hypoglycemic event reported (in the $3.9-5.0 \mathrm{mmol} / \mathrm{L}$ group).

\section{Patient quality of life and treatment satisfaction}

Compared with the data available for the hard endpoints assessed in the clinical trial program, there is a paucity of information with which to evaluate objectively the relative patient acceptability of insulin detemir. Intuitively, its reduced propensity for causing weight gain and low risk of hypoglycemia should translate into patient preferences, given that these are well-known patient concerns. Treatment satisfaction should not be underestimated as an endpoint because this will ultimately affect adherence and uptake, and hence patient prognosis. ${ }^{12}$ Indeed, patient (and prescriber) resistance to the initiation of insulin therapy and nonadherence to prescribed insulin injection regimens are documented problems. ${ }^{113-115}$ In this respect, modern injection devices, such as FlexPen ${ }^{\circledR}$ (Novo Nordisk, Bagsværd, Denmark), in which insulin detemir is presented, are known to facilitate patient acceptance, ${ }^{116}$ as well as dosing accuracy, ${ }^{117}$ while insulin analogs in general are often reported to provide greater treatment satisfaction and adherence than comparable human insulin-based formulations, presumably reflecting their improved tolerability. ${ }^{118}$

A telephone-based survey of 586 insulin detemir users found that patients associated the drug with improved awareness of blood glucose levels, increased confidence in glycemic control, increased confidence in avoiding hypoglycemia, avoidance of weight gain, and improved satisfaction with treatment versus prior insulins. ${ }^{119}$ An analyses of a cohort of type 1 diabetes patients in Belgium who switched their basal insulin to insulin detemir in the PREDICTIVE study also reported a significant improvement in treatment satisfaction, ${ }^{120}$ although it should be noted that this might have been a selfselected group in which there had been atypically poor performance of previous insulin regimens.

\section{Cost-effectiveness}

Modern insulin analogs, including insulin detemir, have higher direct costs than conventional previous insulins, including NPH insulin. However, improvements in diabetes outcome and reductions in adverse events will lead to indirect cost reductions related to the management of diabetes and its complications, as well as potentially improving the life expectancy and quality of life of patients. It is therefore possible that analogs are cost-effective, although this can only really be tested in health economics models that make assumptions based on the trial data. It is noteworthy that several such analyses from different countries have suggested that insulin detemir is indeed cost-effective compared with conventional NPH insulin. ${ }^{121-124}$ In addition, analyses of the projected costs and benefits of converting patients poorly responsive to OADs or other basal insulins plus OADs to insulin detemir plus OADs have suggested that this will be a cost-effective therapy change. ${ }^{125,126}$

\section{Conclusions and future perspectives}

Subcutaneous insulin injection therapy will remain the mainstay of antihyperglycemic therapy for type 1 and advancing type 2 diabetes for the foreseeable future, and while new concerns have emerged about possible morbid outcomes with 
certain agents or therapeutic approaches, there remains no doubt that diligent blood glucose control will positively affect both macro- and microvascular prognosis. To this end, the available evidence suggests that it is important to establish and maintain glycemic control as early as possible following diagnosis, to limit hypoglycemia, glycemic variability, and weight gain, and to manage other risk factors energetically, such as lipid profile, blood pressure and CV risk factors, including hyperinsulinemia. While, as is so often the case with individual pharmacologic agents, we lack direct evidence for the relative prognostic impact of insulin detemir, it does have a profile that appears attractive in the context of diabetes and risk management when compared with earlier basal insulins. It carries a low risk of hypoglycemia, is characterized by relatively low blood glucose variability, and relative avoidance of weight gain, possibly reflecting a more physiologic pattern of tissue action than can be achieved with other subcutaneously administered insulins.

This last point raises an issue in which we might expect to see future developments. The development and study of detemir and other analogs has shown that it might be possible to produce designer insulins that have a modified pattern of tissue distribution/action. It is certainly possible to produce insulin analogs which have receptor interaction profiles that differ from human insulin. ${ }^{24,44}$ Thus, while the preclinical development of insulin detemir originally focused on preserving the receptor-binding profile of human insulin (and the avoidance of increased mitogenic potential will certainly continue to feature in the next generation of insulin analogs), it is possible that future analogs could be designed to have specific modified tissue or receptor actions. An understanding of how insulin detemir avoids the weight gain typical with other basal insulins might also inform future analog development. ${ }^{29}$ The next generation of basal insulin analogs, however, is likely to differ from today's products primarily only in terms of kinetics. In development are some very long-acting basal insulins with the potential to be injected less frequently than once a day, and/or to achieve very flat and stable steady-state kinetics that should further benefit glycemic control and tolerability.

It is possible that refinements in the technology of exogenous insulin delivery will one day render subcutaneous injection (and hence even basal insulin products) obsolete. It is also possible that, as more becomes understood about the etiology of CVD in the setting of diabetes and blood glucose concentration, we might see significant modifications made to guideline treatment algorithms. In the meantime, however, we can expect to see a continuing increase in the use of basal insulin analogs as starter regimens in type 2 diabetes and as standard components of basal + bolus insulin therapy. The clinical trial data suggest that analogs like insulin detemir are already improving glycemic control and/ or tolerability for many insulin dependent patients, and it is hoped that their prognoses will benefit accordingly.

\section{Acknowledgments}

The author is grateful to Watermeadow Medical, Witney, UK, who provided assistance in drafting the manuscript for this invited review. Their work was sponsored by Novo Nordisk, Bagsværd, Denmark.

\section{Disclosure}

The author received research grants from and/or is a member of the boards of the following companies: Abbott Diabetes Care, Becton Dickinson Europe, Merck, MSD, Novalab, Novo Nordisk Pharmaceutical and sanofi-aventis.

\section{References}

1. AACE. Medical guidelines for clinical practice for the management of diabetes mellitus. Endocrine Pract. 2007;13 Suppl 1:S1-S68.

2. Brez S, Rowan M, Malcolm J, et al. Transition from specialist to primary diabetes care: A qualitative study of perspectives of primary care physicians. BMC Fam Pract. 2009;6;10:39.

3. Rolla AR. Addressing the need to tailor treatment to the spectrum of type 2 diabetes: New perspectives. Diabetes Technol Ther. 2009;11: 267-274.

4. Action to Control Cardiovascular Risk in Diabetes Study Group (ACCORD). Effects of intensive glucose lowering in type 2 diabetes. N Engl J Med. 2008;358:2545-2559.

5. ADVANCE Collaborative Group. Intensive blood glucose control and vascular outcomes in patients with type 2 diabetes. $N$ Engl J Med. 2008;358:2560-2572.

6. Duckworth W, Abraira C, Moritz T, et al; VADT Investigators. Glucose control and vascular complications in veterans with type 2 diabetes. $N$ Engl J Med. 2009;360:129-139.

7. Skyler JS, Bergenstal R, Bonow RO, et al; American Diabetes Association; American College of Cardiology Foundation; American Heart Association. Intensive glycemic control and the prevention of cardiovascular events: Implications of the ACCORD, ADVANCE, and VA Diabetes Trials: A position statement of the American Diabetes Association and a Scientific Statement of the American College of Cardiology Foundation and the American Heart Association. J Am Coll Cardiol. 2009;53:298-304.

8. Meier M, Hummel M. Cardiovascular disease and intensive glucose control in type 2 diabetes mellitus: Moving practice toward evidencebased strategies. Vasc Health Risk Manag. 2009;5:859-871.

9. Diabetes Control and Complications Trial/Epidemiology of Diabetes Interventions and Complications (DCCT/EDIC) Study Research Group. 'Intensive diabetes treatment and cardiovascular disease in patients with type 1 diabetes. $N$ Engl J Med. 2005;353:2643-2653.

10. Holman RR, Paul SK, Bethel MA, Matthews DR, Neil HAW. 10-year follow-up of intensive glucose control in type 2 diabetes. NEngl J Med. 2008;359:1577-1589.

11. Karalliedde J, Gnudi L. ACCORD and ADVANCE: A tale of two studies on the merits of glycaemic control in type 2 diabetic patients. Nephrol Dial Transplant. 2008;23:1796-1798.

12. Currie CJ, Peters JR, Tynan A, et al. Survival as a function of $\mathrm{HbA}(1 \mathrm{c})$ in people with type 2 diabetes: A retrospective cohort study. Lancet. 2010;375:481-489. 
13. Sheldon B, Russell-Jones D, Wright J. Insulin analogues: An example of applied medical science. Diabetes Obes Metab. 2009;11:5-19.

14. Hemkens LG, Grouven U, Bender R, et al. Risk of malignancies in patients with diabetes treated with human insulins or insulin analogues - a cohort study. Diabetologia. 2009;52:1745-1754.

15. Colhourn HM, SDRN Epidemiology Group. Use of insulin glargine and cancer incidence in Scotland: A study from the Scottish Diabetes Research Network Epidemiology Group. Diabetologia. 2009;52:1755-1765.

16. Currie JM, Poole CD, Gale EAM. The influence of glucose-lowering therapies on cancer risk in type 2 diabetes. Diabetologia. 2009;52: 1766-1777.

17. Jonasson JM, Ljung R, Talback M, Haglund B, Gudbjornsdottir S, Steineck G. Insulin glargine use and short-term incidence of malignancies - a population-based follow-up study in Sweden. Diabetologia. 2009;52:1745-1754.

18. Home PD, Lagarenne P. Combined randomised controlled trial experience of malignancies in studies using insulin glargine. Diabetologia. 2009;52:2499-2506.

19. Dejgaard A, Lyngaard H, Rastam J, Krogsgaard Thomsen M. No evidence of increased risk of malignancies in patients with diabetes treated with insulin detemir: A meta-analysis. Diabetologia. 2009;52:2507-2512.

20. Smith U, Gale EAM. Does diabetes therapy influence the risk of cancer? Diabetologia. 2009;52:1699-1708.

21. Evans JM, Donnelly LA, Emslie-Smith AM, Alessi DR, Morris AD. Metformin and reduced risk of cancer in diabetic patients. $B M J$. 2005;330:1304-1305.

22. Libby G, Donnelly LA, Donnan PT, Alessi DR, Morris AD, Evans JM. New users of metformin are at low risk of incident cancer: A cohort study among people with type 2 diabetes. Diabetes Care. 2009;32: 1620-1625.

23. Jiralerspong S, Palla SL, Giordano SH, et al. Metformin and pathologic complete responses to neoadjuvant chemotherapy in diabetic patients with breast cancer. J Clin Oncol. 2009;27:3297-3302.

24. Pollak M, Russell-Jones D. Insulin analogues and cancer risk: Cause for concern or cause celébre? Int J Clin Pract. 2010 Feb 26. [Epub ahead of print].

25. Devries JH, Nattrass M, Pieber TR. Refining basal insulin therapy: What have we learned in the age of analogues? Diabetes Metab Res Rev. 2007;23:441-454.

26. Holman RR, Farmer AJ, Davies MJ, et al; 4-T Study Group. Three-year efficacy of complex insulin regimens in type 2 diabetes. $N$ Engl J Med. 2009;361:1736-1747.

27. Lasserson DS, Glasziou P, Perera R, Holman RR, Farmer AJ. Optimal insulin regiments in type 2 diabetes mellitus: Systematic review and meta-analyses. Diabetologia. 2009;52:1990-2000.

28. Heise T, Nosek L, Ronn BB, et al. Lower within-subject variability of insulin detemir in comparison to NPH insulin and insulin glargine in subjects with type 1 diabetes. Diabetes. 2004;53:1614-1620.

29. Russell-Jones D, Khan R. Insulin-associated weight gain in diabetes causes, effects and coping strategies. Diabetes Obes Metab. 2007;9: 799-812.

30. Owens DR, Bolli GB. Beyond the era of NPH insulin - long-acting insulin analogs: Chemistry, comparative pharmacology, and clinical application. Diabetes Technol Ther. 2008;10:333-349.

31. Kurtzhals P, Havelund S, Jonassen I, Markussen J. Effect of fatty acids and selected drugs on the albumin binding of a long-acting, acylated insulin analogue. J Pharm Sci. 1997;86:1365-1368.

32. Havelund S, Plum A, Ribel U, et al. The mechanism of protraction of insulin detemir, a long-acting, acylated analog of human insulin. Pharm Res. 2004;21:1498-1504.

33. Kurtzhals P. Engineering predictability and protraction in a basal insulin analogue: The pharmacology of insulin detemir. Int $J$ Obes. 2004;28: S23-S28.

34. Klein O, Lynge J, Endahl L, Damholt B, Nosek L, Heise T. Albuminbound basal insulin analogues (insulin detemir and NN344): Comparable time-action profiles but less variability than insulin glargine in type 2 diabetes. Diabetes Obes Metab. 2007;9:290-299.
35. Heise T, Pieber TR. Towards peakless, reproducible and long-acting insulins. An assessment of the basal analogues based on isoglycaemic clamp studies. Diabetes Obes Metab. 2007;9:648-659.

36. Bush MA. Intensive diabetes therapy and body weight: Focus on insulin detemir. Endocrinol Metab Clin North Am. 2007;36 Suppl 1:33-44.

37. Hordern SV, Wright JE, Umpleby AM, Shojaee-Moradie F, Amiss J, Russell-Jones DL. Comparison of the effects on glucose and lipid metabolism of equipotent doses of insulin detemir and NPH insulin with a 16-h euglycaemic clamp. Diabetologia. 2005;48: 420-426.

38. Smeeton F, Shojaee Moradie F, Jones RH, et al. Differential effects of insulin detemir and neutral protamine Hagedorn (NPH) insulin on hepatic glucose production and peripheral glucose uptake during hypoglycaemia in type 1 diabetes. Diabetologia. 2009;52: 2317-2323.

39. Tschritter O, Hennige AM, Preissl H, et al. Cerebrocortical beta activity in overweight humans responds to insulin detemir. PLOS ONE. 2007; 2:e1196.

40. Sharma MD, Garber AJ, Farmer JA. Role of insulin signaling in maintaining energy homeostasis. Endocr Pract. 2008;14:373-380.

41. Bohm A, Staiger H, Hennige AM, Haas C, Machicao F, Hring HU. Effect of insulin detemir, compared to human insulin, on 3T3-L1 adipogenesis. Regul Pept. 2008;151:160-163.

42. Pocock SJ, Smeeth L. Insulin glargine and malignancy: An unwarranted alarm. Lancet. 2009;374:511-513.

43. Rosenstock J, Fonseca V, McGill JB, et al. Similar risk of malignancy with insulin glargine and neutral protamine Hagedorn (NPH) insulin in patients with type 2 diabetes: Findings from a 5 year randomised, open-label study. Diabetologia. 2009;52:1971-1973.

44. Kurtzhals P, Schaffer L, Sorensen A, et al. Correlations of receptor binding and metabolic and mitogenic potencies of insulin analogs designed for clinical use. Diabetes. 2000;49:999-1005.

45. Shukla A, Grisouard J, Ehemann V, Hermani A, Enzmann H, Mayer D. Analysis of signaling pathways related to cell proliferation stimulated by insulin analogs in human mammary epithelial cell lines. Endocr Relat Cancer. 2009;16:429-441.

46. Wada T, Azegami M, Sugiayama M, Tsuneki H, Sasaoka T. Characteristics of signalling properties mediated by long-acting insulin analogue glargine and detemir in target cells of insulin. Diab Res Clin Pract. 2008;81:269-277.

47. Hansen BF, Danielsen GM, Drejer K, et al. Sustained signalling from the insulin receptor after stimulation with insulin analogues exhibiting increased mitogenic potency. Biochem J. 1996;315(Pt 1):271-279.

48. Home P, Bartley P, Russell-Jones DL, et al. Insulin detemir offers improved glycemic control compared with NPH insulin in people with type 1 diabetes: A randomized clinical trial. Diabetes Care. 2004;27: 1081-1087.

49. Kolendorf K, Ross GP, Pavlic-Renar I, et al. Insulin detemir lowers the risk of hypoglycemia and provides more consistent plasma glucose levels compared with NPH insulin in type 1 diabetes. Diabet Med. 2006;23:729-735.

50. Pieber TR, Draeger E, Kristensen A, Grill V. Comparison of three multiple injection regimens for type 1 diabetes: Morning plus dinner or bedtime administration of insulin detemir vs morning plus bedtime NPH insulin. Diabet Med. 2005;22:850-857.

51. Pieber TR, Treichel HC, Hompesch B, et al. Comparison of insulin detemir and insulin glargine in subjects with type 1 diabetes using intensive insulin therapy. Diabet Med. 2007;24:635-642.

52. Russell-Jones DL, Simpson R, Hylleberg B, Draeger E, Bolinder J. Effects of QD insulin detemir or neutral protamine Hagedorn on blood glucose control in patients with type 1 diabetes mellitus using a basalbolus regimen. Clin Ther. 2004;26:724-736.

53. Hermansen K, Fontaine P, Kukolja K, Peterkova V, Leth G, Gall M-A. Insulin analogues (insulin detemir and insulin aspart) versus traditional human insulins (NPH insulin and regular human insulin) in basal-bolus therapy for patients with type 1 diabetes. Diabetologia. 2004;47: 622-629. 
54. Bartley PC, Bogoev M, Larsen J, Philotheou A. Long-term efficacy and safety of insulin detemir compared to neutral protamine Hagedorn insulin in patients with type 1 diabetes using a treat-to-target basal-bolus regimen with insulin aspart at meals: A 2-year, randomized, controlled trial. Diabet Med. 2008;25:442-449.

55. Le Floch JP, Lévy M, Mosnier-Pudar H, et al; and the ADAPT'M Study Group. A comparison of once- versus twice-daily administration of insulin detemir, used with mealtime insulin aspart, in basal-bolus therapy for type 1 diabetes: The ADAPT ${ }^{\mathrm{TM}}$ Study. Diabetes Care 2009;32:32-37.

56. Robertson KJ, Schoenle E, Gucev Z, Mordhorst L, Gall MA, Ludvigsson J. Insulin detemir compared with NPH insulin in children and adolescents with type 1 diabetes. Diabet Med. 2007;24:27-34.

57. Braun D, Konrad D, Lang-Muritano M, Schoenle E. Improved glycemic control and lower frequency of severe hypoglycemia with insulin detemir; long-term experience in 105 children and adolescents with type 1 diabetes. Pediatr Diabetes. 2008;9(4 pt 2):382-387.

58. Robertson KJ, Schonle E, Gucev Z, et al. Benefits of insulin detemir over NPH insulin in children and adolescents with type 1 diabetes: Lower and more predictable fasting plasma glucose and lower risk of nocturnal hypoglycemia. Diabetes. 2004;53:A144.

59. Heller S, Koenen C, Bode B. Comparison of insulin detemir and insulin glargine in a basal-bolus regimen, with insulin aspart as the mealtime insulin, in patients with type 1 diabetes: A 52-week, multinational, randomized, open-label, parallel-group, treat-to-target noninferiority trial. Clin Ther. 2009;31:2086-2097.

60. Garber AJ, Clauson P, Pedersen CB, Kølendorf K. Lower risk of hypoglycemia with insulin detemir than with neutral protamine Hagedorn insulin in older persons with type 2 diabetes: A pooled analysis of phase III trials. J Am Geriatr Soc. 2007;55:1735-1740.

61. Hermansen K, Davies M, Derezinski T, Martinez G, Clauson P, Home P. A 26-week, randomized, parallel, treat-to-target trial comparing insulin detemir with NPH insulin as add-on therapy to oral glucose-lowering drugs in insulin-naïve people with type 2 diabetes. Diabetes Care 2006;29:1269-1274.

62. Rosenstock J, Davies M, Home PD, Larsen J, Tamer SC, Schernthaner G. Insulin detemir added to oral anti-diabetic drugs in type 2 diabetes provides glycemic control comparable to insulin glargine with less weight gain. Diabetes. 2006;55:A132.

63. Haak T, Tiengo A, Draeger E, Suntum M, Waldhausl W. Lower withinsubject variability of fasting blood glucose and reduced weight gain with insulin detemir compared to NPH insulin in patients with type 2 diabetes. Diabetes Obes Metab. 2005;7:56-64.

64. Raslova K, Bogoev M, Raz I, Leth G, Gall M-A, Hancu N. Insulin detemir and insulin aspart: A promising basal-bolus regimen for type 2 diabetes. Diabetes Res Clin Pract. 2004;66:193-201.

65. Philis-Tsimikas A, Charpentier G, Clauson P, Ravn GM, Roberts VL, Thorsteinsson B. Comparison of once-daily insulin detemir with NPH insulin added to a regimen of oral antidiabetic drugs in poorly controlled type 2 diabetes. Clin Ther. 2006;28:1569-1581.

66. Rosenstock J, Davies M, Home PD, Larsen J, Koenen C, Schernthaner G. A randomised, 52-week, treat-to-target trial comparing insulin detemir with insulin glargine when administered as add-on to glucose-lowering drugs in insulin-naive people with type 2 diabetes. Diabetologia. 2008;51:408-416.

67. Hollander P, Cooper J, Bregnhøj J, Pedersen CB. A 52-week, multinational, open-label, parallel-group, noninferiority, treat-to-target trial comparing insulin detemir with insulin glargine in a basal-bolus regimen with mealtime insulin aspart in patients with type 2 diabetes. Clin Ther 2008;30:1976-1987.

68. Home P, Kurtzhals P. Insulin detemir: From concept to clinical experience. Expert Opin Pharmacother. 2006;7:325-343.

69. Danne T, Datz N, Endahl L, et al. Insulin detemir is characterized by a more reproducible pharmacokinetic profile than insulin glargine in children and adolescents with type 1 diabetes: Results from a randomized, double-blind, controlled trial. Pediatr Diabetes. 2008;9:554-560.
70. Monnier L, Colette C, Mas E, et al. Regulation of oxidative stress by glycaemic control: Evidence for an independent inhibitory effect of insulin therapy. Diabetologia. 2010;53:562-571.

71. Monnier L, Mas E, Ginet C, et al. Activation of oxidative stress by acute glucose fluctuations compared with sustained chronic hyperglycemia in patients with type 2 diabetes. JAMA. 2006;295:1681-1687.

72. Ceriello A, Esposito K, Piconi L, et al. Oscillating glucose is more deleterious to endothelial function and oxidative stress than mean glucose in normal and type 2 diabetic patients. Diabetes. 2008;57: 1349-1354.

73. Brownlee M, Hirsch IB. Glycemic variability: A hemoglobin $A_{1 c^{-}}$ independent risk factor for diabetic complications. JAMA. 2006;295: $1707-1708$.

74. Lachin JM, Genuth S, Nathan DM, Zinman B, Rutledge BN; DCCT/ EDIC Research Group. Effect of glycemic exposure on the risk of microvascular complications in the diabetes control and complications trial revisited. Diabetes. 2008;57:995-1001.

75. Kilpatrick ES, Rigby AS, Atkin SL. Effect of glucose variability on the long-term risk of microvascular complications in type 1 diabetes. Diabetes Care. 2009;32:1901-1903.

76. Niskanen L, Virkamäki A, Hansen JB, Saukkonen T. Fasting plasma glucose variability as a marker of nocturnal hypoglycemia in diabetes: Evidence from the PREDICTIVETM study. Diabetes Res Clin Pract. 2009;86:e15-e18.

77. Meneghini L, Liebl A, Abrahamson M. Insulin detemir: A historical perspective on a modern basal analogue insulin. Prim Care Diabetes. 2010;4(1):S31-S42.

78. Raslová K, Tamer SC, Clauson P, Karl D. Insulin detemir results in less weight gain than NPH insulin when used in basal-bolus therapy for type 2 diabetes mellitus, and this advantage increases with baseline body mass index. Clin Drug Investig. 2007;27:279-285.

79. Philis-Tsimikas A. Tolerability, safety and adherence to treatment with insulin detemir injection in the treatment of type 2 diabetes. Patient Prefer Adherence. 2008;2:323-332.

80. Dornhorst A, Lüddeke HJ, Koenen C, et al; PREDICTIVE Study Group. Transferring to insulin detemir from NPH insulin or insulin glargine in type 2 diabetes patients on basal-only therapy with oral antidiabetic drugs improves glycaemic control and reduces weight gain and risk of hypoglycaemia: 14-week follow-up data from PREDICTIVE. Diabetes Obes Metab. 2008;10:75-81.

81. Dornhorst A, Lüddeke HJ, Sreenan S, et al; PREDICTIVE Study Group. Insulin detemir improves glycaemic control without weight gain in insulin-naïve patients with type 2 diabetes: Subgroup analysis from the PREDICTIVE study. Int J Clin Pract. 2008;62:659-665.

82. Eeg-Olofsson K, Cederholm J, Nilsson PM, et al. Risk of cardiovascular disease and mortality in overweight and obese patients with type 2 diabetes: An observational study in 13,087 patients. Diabetologia. 2009;52:65-73.

83. Anderson JW, Konz EC. Obesity and disease management: Effects of weight loss on comorbid conditions. Obes Res. 2001;9 Suppl 4: 326S-334S.

84. Fledelius C, Damgaard J, Vinterby A, Ribel U, Petersen JS. Insulin detemir results in less body weight and fat mass increase than both NPH and insulin glargine in the ZDF rat. Presented at: 68th annual meeting of the American Diabetes Association. 2008 June 6-10, San Francisco, California. Poster 497

85. Tinahones FJ, Martin M, Cardona F, Macias-Gonzalez M. Visceral fat mass in patients with type 2 diabetes is reduced during insulin detemirbased basal bolus therapy, whereas it is increased during NPH-insulin based basal bolus therapy. Obesity \& Metabolism. 2008;4:165-168.

86. Mandosi E, Fallarino M, Rossetti M, Gatti A, Morano S. Waist circumference reduction after insulin detemir therapy in type 2 diabetes patients previously treated with NPH. Diabetes Res Clin Pract. 2009;84: e18-e20.

87. Polonsky KS, Gumbiner B, Ostrega D, Griver K, Tager H, Henry RR. Alterations in immunoreactive proinsulin and insulin clearance induced by weight loss in NIDDM. Diabetes. 1994;43:871-877. 
88. Bryden KS, Neil A, Mayou RA, Peveler RC, Fairburn CG, Dunger DB. Eating habits, body weight, and insulin misuse. A longitudinal study of teenagers and young adults with type 1 diabetes. Diabetes Care. 1999;22:1956-1960.

89. Herpertz S, Albus C, Wagener R, et al. Comorbidity of diabetes and eating disorders. Does diabetes control reflect disturbed eating behavior? Diabetes Care. 1998;21:1110-1116.

90. Reaven G. Metabolic syndrome. Pathophysiology and implications for management of cardiovascular diseases. Circulation. 2002;106: 286-288.

91. Grundy SM, Brewer B, Cleeman JI, Smith SC, Lenfant C. Defintion of metabolic syndrome. Report of the National Heart Lung and Blood Institute/American Heart Association Conference on scientific issues related to definition. Circulation. 2004;109:433-438.

92. Dornhorst A, Luddeke H-J, Sreenan S, et al; PREDICTIVE Study Group. Safety and efficacy of insulin detemir in clinical practice: 14-week follow-up data from type 1 and type 2 diabetes patients in the PREDICTIVE European cohort. Int J Clin Pract. 2007;61: 523-528.

93. Dornhorst A, Lüddeke HJ, Honka M, et al; PREDICTIVE Study Group. Safety and efficacy of insulin detemir basal-bolus therapy in type 1 diabetes patients: 14-week data from the European cohort of the PREDICTIVE study. Curr Med Res Opin. 2008;24:369-376.

94. Sreenan S, Virkamki A, Zhang K, Hansen JB; PREDICTIVE study group. Switching from NPH insulin to once-daily insulin detemir in basal-bolus-treated patients with diabetes mellitus: Data from the European cohort of the PREDICTIVE study. Int J Clin Pract. 2008;62: 1971-1980.

95. Yenigun M, Honka M. Switching patients from insulin glargine-based basal-bolus regimens to a once daily insulin detemir-based basal-bolus regimen: Results from a subgroup of the PREDICTIVE study. Int $J$ Clin Pract. 2009;63:425-432.

96. Kurtoglu S, Atabek ME, Dizdarer C, Pirgon O, Isguven P, Emek S; PREDICTIVE Turkey Study Group. Insulin detemir improves glycemic control and reduces hypoglycemia in children with type 1 diabetes: Findings from the Turkish cohort of the PREDICTIVE observational study. Pediatr Diabetes. 2009;10:401-407.

97. Meneghini L, Koenen C, Weng W, Selam JL. The usage of a simplified self-titration dosing guideline (303 Algorithm) for insulin detemirin patients with type 2 diabetes - results of the randomized,controlled PREDICTIVE 303 study. Diabetes Obes Metab. 2007;9:902-913.

98. Meneghini LF, Rosenberg KH, Koenen C, Merilainen MJ, Luddeke H-J. Insulin detemir improves glycemic control with less hypoglycemia and no weight gain in patients with type 2 diabetes who were insulin naïve or treated with NPH or insulin glargine: Clinical practice experience from a German subgroup of the PREDICTIVE study. Diabetes Obes Metab. 2007;9:418-427.

99. Meneghini LF, Dornhorst A, Sreenan S; PREDICTIVE Study Group. Once-daily insulin detemir in a cohort of insulin-naïve patients with type 2 diabetes: A sub-analysis from the PREDICTIVE study. Curr Med Res Opin. 2009;25:1029-1035.

100. Knerr I, Hofer SE, Holterhus PM, et al. Prevailing therapeutic regimes and predictive factors for prandial insulin substitution in 26,687 children and adolescents with type 1 diabetes in Germany and Austria. Diabet Med. 2007;24:1478-1481.

101. Honka M. [Results of the PREDICTIVE project in the Czech Republic]. Vnitr Lek. 2008;54:361-367. Czech.

102. Philips JC, Scheen AJ. [Insulin detemir in the predictive study: Results in patients with type 1 diabetes in the Belgian cohort]. Rev Med Liege. 2009;64:124-130. French.

103. Plank J, Bodenlenz M, Sinner F, et al. A double-blind, randomized, dose-response study investigating the pharmacodynamic and pharmacokinetic properties of the long-acting insulin analog detemir. Diabetes Care. 2005;28:1107-1112.
104. Riddle MC, Rosenstock J, Gerich J; Insulin Glargine 4002 Study Investigators. The treat-to-target trial: Randomized addition of glargine or human NPH insulin to oral therapy of type 2 diabetic patients. Diabetes Care. 2003;26:3080-3086.

105. Bruce DG, Chisholm DJ, Storlien LH, Kraegen EW. Physiological importance of deficiency in early prandial insulin secretion in noninsulin-dependent diabetes. Diabetes. 1988;37:736-744.

106. Ashwell SG, Gebbie J, Home PD. Twice-daily compared with once-daily insulin glargine in people with type 1 diabetes using mealtime insulin aspart. Diabet Med. 2006;23:879-886.

107. Clement S, Bowen-Wright $H$. Twenty-four hour action of insulin glargine (Lantus) may be too short for once-daily dosing: A case report. Diabetes Care. 2002;25:1479-1480.

108. Fontaine P, Gin H, Pinget M, et al. Effect of insulin detemir dose frequency on clinical outcomes in patients with diabetes in PREDICTIVE. Adv Ther. 2009;26:535-551.

109. Blonde L, Merilainen M, Karwe V, Raskin P; TITRATE Study Group. Patient-directed titration for achieving glycaemic goals using a oncedaily basal insulin analogue: An assessment of two different fasting plasma glucose targets - the TITRATE study. Diabetes Obes Metab. 2009;11:623-631.

110. Selam JL, Koenen C, Weng W, Meneghini L. Improving glycemic control with insulin detemir using the 303 Algorithm in insulin naïve patients with type 2 diabetes: A subgroup analysis of the US PREDICTIVE 303 study. Curr Med Res Opin. 2008;24:11-20.

111. Selam JL, Meneghini LF. Basal-bolus therapy with insulin detemir using the 303 algorithm in the US PREDICTIVE 303 trial. Adv Ther. 2009;26:194-207.

112. Fu AZ, Qiu Y, Radican L. Impact of fear of insulin or fear of injection on treatment outcomes of patients with diabetes. Curr Med Res Opin. 2009;25:1413-1420.

113. Cramer JA. A systematic review of adherence with medications for diabetes. Diabetes Care. 2004;27:1218-1224.

114. Peyrot M, Rubin RR, Lauritzen T, et al; International DAWN Advisory Panel. Resistance to insulin therapy among patients and providers: Results of the cross-national Diabetes Attitudes, Wishes, and Needs (DAWN) study. Diabetes Care. 2005;28:2673-2679.

115. Brod M, Kongsø JH, Lessard S, Christensen TL. Psychological insulin resistance: Patient beliefs and implications for diabetes management. Qual Life Res. 2009;18:23-32.

116. Goldstein HH. Pen devices to improve patient adherence with insulin therapy in type 2 diabetes. Postgrad Med. 2008;120:172-179.

117. Hänel H, Weise A, Sun W, Pfützner JW, Thomé N, Pfützner A. Differences in the dose accuracy of insulin pens. J Diabetes Sci Technol. 2008;2:478-481.

118. Hartman I. Insulin analogs: Impact on treatment success, satisfaction, quality of life, and adherence. Clin Med Res. 2008;6:54-67.

119. Kerney DL, Paradis D, Brunton S. Patient perceptions of insulin detemir as reported through patient telephone surveys. Curr Med Res Opin. 2007;23:2043-2049.

120. Preumont V, Buysschaert M, De Beukelaer S, Mathieu C. Insulin detemir in routine clinical practice: A 26-week follow-up in type 1 diabetic patients from the Belgian PREDICTIVE Cohort. Acta Clin Belg. 2009;64:49-55.

121. Valentine WJ, Palmer AJ, Erny-Albrecht KM, et al. Cost-effectiveness of basal insulin from a US health system perspective: Comparative analyses of detemir, glargine, and NPH. Adv Ther. 2006;23: 191-207.

122. Gschwend MH, Mark Aagren M, Valentine MJ. Cost-effectiveness of insulin detemir compared with neutral protamine Hagedorn insulin in patients with type 1 diabetes using a basal-bolus regimen in five European countries. J Med Econ. 2009;12:114-123.

123. Tunis SL, Minshall ME, Conner C, et al. Cost-effectiveness of insulin detemir compared to NPH insulin for type 1 and type 2 diabetes mellitus in the Canadian paying setting: Modeling analysis. Curr Med Res Opin. 2009;25:1273-1284. 
124. Palmer AJ, Valentine WJ, Ray JA, et al. An economic assessment of analogue basal-bolus insulin versus human basal-bolus insulin in subjects with type 1 diabetes in the UK. Curr Med Res Opin. 2007; 23:895-901.

125. Valentine WJ, Erny-Albrecht KM, Ray JA, Roze S, Cobden D, Palmer AJ. Therapy conversion to insulin detemir among patients with type 2 diabetes treated with oral agents: A modeling study of cost-effectiveness in the United States. Adv Ther. 2007;24:273-290.
126. Valentine WJ, Goodall G, Aagren M, Nielsen S, Palmer AJ, Erny-Albrecht K. Evaluating the cost-effectiveness of therapy conversion to insulin detemir in patients with type 2 diabetes in Germany: A modelling study of long-term clinical and cost outcomes. Adv Ther. 2008;25:567-584.

\section{Publish your work in this journal}

Diabetes, Metabolic Syndrome and Obesity: Targets and Therapy is an international, peer-reviewed open-access journal committed to the rapid publication of the latest laboratory and clinical findings in the fields of diabetes, metabolic syndrome and obesity research. Original research, review, case reports, hypothesis formation, expert opinion and commentaries are all considered for publication. The manuscript management system is completely online and includes a very quick and fair peer-review system, which is all easy to use. Visit http://www. dovepress.com/testimonials.php to read real quotes from published authors.

Submit your manuscript here: http://www.dovepress.com/diabetes-metabolic-syndrome-and-obesity-targets-and-therapy-journal 